\title{
LXI. On the duty of steam-engines in Cornwall
}

\section{John Taylor Esq. F.R.S.}

To cite this article: John Taylor Esq. F.R.S. (1830) LXI. On the duty of steam-engines in Cornwall , Philosophical Magazine Series 2, 7:42, 424-431, DOI: 10.1080/14786443008675330

To link to this article: http://dx.doi.org/10.1080/14786443008675330

$$
\text { 曲 Published online: } 13 \text { Jul } 2009 .
$$

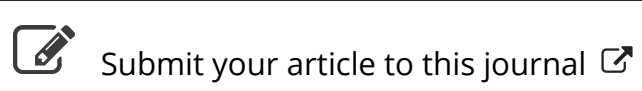

\footnotetext{
Џ Article views: 2
}

Q View related articles $₫$ 
vention of expansive working, why is high pressure steam used in Cornwall? explosions have been frequent enough* to deter the miners from continuing the use of such a dangerous agent, if they could carry on deep mining without its aid.

The obvious intention of the communication at p. 324 is to lead your readers to conclude that Mr. Woolf's patent was for no invention at all, and that the system of working steamengines by high pressure steam acting expansively (which he alone introduced into use) has had nothing to do with the remarkable improvement of the performance of engines in Cornwall, within the last seventeen years.

The mention I made of $\mathrm{Mr}$. Woolf's invention, arose incidentally in answering the various questions put by the Committee. I cited $\mathrm{Mr}$. Woolf as an example of the case that has so often occurred, where an inventor who has rendered inportant service to the public, has derived no benefit from his patent, because it expired before the invention came into use; and I also cited Mr. Watt, as an example of the rare case of an inventor who did derive an adequate recompense for his public services, by the operation of an Act of Parliament, which prolonged the term of his patent.

If any member of the Committee had felt doubtful of the accuracy of my statement, further questions would certainly have been put, either to me or to others. I was fully prepared to substantiate all $I$ advanced; and if you think it will prove interesting to your readers, you can reprint from the evidence reported by the Committee all that relates to $\mathrm{Mr}$. Woolf, and I will supply you with the explanation which I should have given in support of my statement, if it had been called for.

I am, Dear Sir, yours truly,

37, Howland-Street, Fitzroy.Square,

John Farey. May 10,1830 .

[We shall gladly avail ourselves of Mr. Farey's offer of further information on this important subject. It is due to the memory of our estimable predecessor, Dr. Tilloch, to state that, so far as pecuniary means have contributed to the completion of $\mathrm{Mr}$. Woolf's invention, the public are in a great measure indebted to him for it.]-EDrr. :

LXI. On the Duty of Steam-Engines in Cornwall. By JoHn TAYLOR, Esq. F.R.S. \&c.

To the Editors of the Philosophical Magazine and Annals. Gentlemen,

THE attention of the Admiralty has, it appears, lately been drawn to the subject of the duty performed by the steamengines in Cornwall. This is said to have been done by Cap-

* See Mr. John Taylor's paper on this subject in vol. i. of the present series of the Philosophical Magazine, p. 126, also p. 403. 
tain King, superintendant of the packets at Falmouth, and in consequence Mr. Rennie has been desired to investigate the facts.

This gentleman lately visited Cornwall, and selected for experiment Wilson's engine at Wheal Towan, erected by Capt. Samuel Grose, which has for two years past stood highest in the monthly reports, and which is so justly celebrated for its performance and for its general excellence as a pumping-engine.

The following are the particulars and dimensions of the most important parts, as noted by parties present at the mine at the time of the experiment.

Cylinder 80 inches diameter.

Length of stroke in the cylinder 10 feet. in the pumps 8 feet.

Usual rate of working about $6 \frac{1}{2}$ strokes per minute.

Draws 5 lifts of pumps of the following lengths and diameters. Heights.

\begin{tabular}{cc}
$\begin{array}{c}\text { Diameters. } \\
\text { Inches. }\end{array}$ & $\begin{array}{c}\text { Weight. } \\
\text { lbs. } \\
13\end{array}$ \\
15313 \\
$15 \frac{7}{8}$ & 22656 \\
$16 \frac{1}{8}$ & 17525 \\
$17 \frac{7}{8}$ & 12381 \\
12 & 2856 \\
\hline & 70731
\end{tabular}

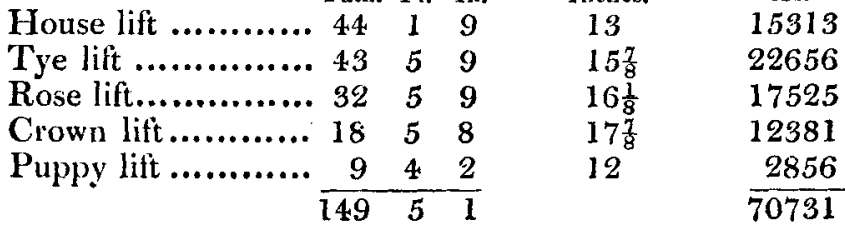

The water contained in this column is 1131.7 cubic feet; weight 70731 pounds; being at the rate of 11.15 pounds per square inch of the piston.

During the experiment made by $\mathrm{Mr}$. Rennie, the engine made 979 strokes and consumed 6 bushels of coal, which gives for duty, according to the preceding data, 92,327,000 pounds lifted one foot by each bushel.

A former experiment on this same engine was made in 1828 , in the presence of several mine agents and engineers, to which I alluded in my paper on the duty of steam-engines, published in the "Records of Mining*," and in which the result was $87,210,000$ pounds lifted one foot by each bushel. I find that the duty reported monthly in the printed duty papers for 1829 , is on an average $76,234,307$; and it was $77,290,000$ in the preceding year, as appears from the statements in the publication to which I have referred.

It is satisfactory to perceive that at length this subject seems likely to receive the attention, and undergo the investigation it deserves. The facts have been long before the public, but they have been much controverted, and rather treated as the statements of visionary or interested persons, than as substan-

* Murray, 1829. Phil. Mag. and Annals, vol. v. p. 297

N.S. Vol. 7. No, 42. June 1830. 
tive results which merited examination. It has been preferred to suppose all kinds of error in the mode of computation or in the data rather than admit their consequences; and this I have reason to think has been done very often where a little inquiry would have produced a satisfactory explanation.

I published my paper in the "Records of Mining," with a view to promote such inquiry: I traced the history of the duty of steam-engines from the earliest period of their application; I endeavoured to show that the standard of comparison, as between one pumping-engine and another, was a fair one, notwithstanding some unimportant imperfections; and that it was to this standard that Messis. Boulton and Watt appealed for proof of the superiority of their engines when engaged in legal disputes respecting their patent rights, or in claiming their allowance for the use of them.

I attempted to correct a misapprehension that I believed to exist as to the purpose of the monthly reports of Duty of Engines in Cornwall, and as to the parties by whom they are caused to be made. I had often heard, and I continue to hear, that they are published by persons concerned in making engines, and that the object might therefore be to exaggerate the value of particular improvements: it has sometimes on the other hand been stated, that they are carelessly or ignorantly done. I showed, in reply to this, that these reports are procured by the adventurers in the Cornish mines, who use engines so extensively as to render them especially concerned in finding out who make them the best, and whose only partiality that I know of, to any construction of an engine is, to that which will do their work at the least expense. The history of the steam-engine will exhibit the same fact; and hence it has been that Newcomen, Smeaton, Watt, Bull, Hornblower, Woolf, Grose, and others, have found in Cornwall the principal field for their first efforts.

The adventurers in deep mines in Cornwall may well desire to know accurately the value of the different applications of steam power; their interest in that question is perhaps greater than that of suly other individuals. One concern with which I am connected, employs 8 engines for drawing water, of which 4 have cylinders of 90 inches in diameter; the monthly consumption of coal is about 14,000 bushels, and the expenses near 12,000l. a-year. But if we take all the mines in the county into consideration, there will appear abundance of reason for great interest in this matter; and the fact being so, how absurd would it be to permit any mode of self-deceit! and how much more absurd to pay liberally for information, on which, according to some, no reliance is to be placed! 
But are all the adventurers in Cornwall likely to be so ignorant? and are they not in a situation to have acquired more experience in engines than most other persons? They have witnessed each step of improvement, they have been parties to the strifes and contentions respecting them, and they can certainly tell by their cost-books whether their saving in coal and in money corresponds or not with the calculations of duty which they receive from the agents whom they employ and pay to furnish them with this information ; and they or their managers can judge whether such agents are competent to the task, and perform it correctly. It has been suggested also, as I hear, that the data are taken in a negligent manner, that pumps are not correctly gauged, that the coal is not measured, and that all is vague and indefinite. Now I have alseady endeavoured to show how important it is thought by the owners of these engines to have a very correct account of their duty. I have stated that they pay liberally for such an account, and that their agents at least are competent to judge of the manner in which it is furnished by the parties specially appointed for the purpose. It is therefore rather too much to suppose gratuitously that the means of obtaining correctness are totally neglected.

I assert, however, that the greatest possible care is taken in all the steps of the process; and this I will endeavour to explain more fully. The duty of the Cornish engines is taken and computed by Messrs. Thomas and John Lean, who publish separate lists of the engines which they respectively have the charge of; the counters are carefully under lock, and no one has access to them but themselves. At some mines other counters are attached for the inspection of the agents, and at the Consolidated Mines a daily computation of duty is made from them, which is posted up in every engine-house on the concern. The average of these, I may observe, is compared with the monthly report, and found generally to coincide as nearly as possible.

The calibre of the pumps is taken occasionally by the reporter; and I have been assured by Captain Thomas Lean, that he does not rely upon any account given to him, but on his own measurements; they are subject to some alteration by wear, which is attended to from time to time. The experiment upon Wheal Towan furnishes some evidence on this point; the diameters of the pumps which I have given above were taken, I presume, to satisfy Mr. Rennie, and they are stated to eighths of an inch; they agree very nearly with those in the report of March by Mr. John Lean. The shortest way, however, of comparing, is by taking the computed weight 
of water by each methor, which, calculated for Mr. Rennie's experiment, was............................ 70,734 pounds.

Stated in duty paper for March 70,605

So that taking diameters and lengths together, they were found rather to exceed the printed account, but differ only by 129 pounds in the whole.

Those who are acquainted with the management of the mines know that the coal is very accurately measured to each engine; both that the duty of the engine may be ascertained, and that the drawback allowed by the Custom-House may be obtained, which is granted on the oath of the parties that the measurements are correct.

I will explain with how much precision this is conducted at the Consolidated Mines. In each engine-house a paper, printed in columns to serve for one month, is placed, called The Engine-men and Coal-measurers' List. The engine-men are required to place in the column, No. 1, a statement of the quantity of coal wanted for the next 24 hours, which is to be done between the hours of 7 and 8 in the morning for every respective day of the month, and where the coal-measurer may refer to know the quantity required. This person delivers the quantity required daily, by accurate measurement, and places the account of what he actually delivers in column, No. 2; and further, one of the engine-men on duty must see the coal delivered into the sheds, keep an account of the measurement, and certify the quantity by marking it in column, No. 3. A penalty is imposed for any neglect of this order.

The engine-men, being to a certain extent responsible for the duty of their engine, ought to see, as they do by this regulation, that they have their proper quantity of coal ; and it is the express purpose of the coal-measurer's office that no more than what is accurately registered be delivered.

But here, again, the experiment on Wheal Towan engine may be quoted; the duty was found to be $92,331,899$. The experiment in 1828 gave a result of $87,000,000$, and the average duty of 12 reports published last year was 76,234,307. Now as the performance of any engine under experiment will be free from those stoppages or hindrances which we know diminish duty, and which cannot be avoided in the work of a month, we may expect that what would be found in the one case would exceed that of the other; and so it proves to be. Now as doubtless Mr. Rennie, and the gentlemen who were with him, took care to see the coal properly measured and applied, it follows that the measurement for the 12 months, of which the duty was reported, was very nearly correct also.

Wheal Towan is a mine which was in full work previous to 
1814, when it was given up. It was undertaken again by the present adventurers in 1826 ; it is not situated near other mines, by which it can be suspected that water is drained from it, or that there is now less to draw than formerly. It is worked deeper than before, and the engines are more loaded in that proportion. As greater steam power must therefore be required than in 1813 ; is that obtained by the use of a smaller quantity of fuel? and if so, is the diminution in quantity proportionate to the improvement in engines, which we say has taken place; and has that improvement been correctly represented in the duty papers? If it should appear to be so, then the measurement of coal, the diameter of the pumps, and all other data, have been correctly assumed and used, and for a long series of years.

I have given in the "Records of Mining" several instances to show that the actual quantities of coal used by different mines have diminished proportionately with the reported improvement in the engines; and I presume it will not be supposed that the account books are incorrect, which show the quantity of coals bought and paid for. I will repeat the case of Wheal Towan, as it appears to me decisive, and as it is one with which I am, personally, totally unconnected, and can have therefore no partialities to bias me.

When the mine ceased to work in 1814, the average monthly consumption of coal had been for some time 9360 bushels; the average duty of engines in Cornwall was then about 20,000,000, according to the tables which I have given, and which we may assume as the performance of those engines for this calculation.

When I wrote my paper in the latter part of 1828 , the monthly consumption of coal at Wheal Towan was but about 2600 bushels, and the average duty of the two engines working was $66,000,000$, as reported in the duty papers.

Now $66,000,000$ is to $20,000,000$ as 9360 is to 2830 , which is sufficiently near to prove the case; and in taking a larger average of the coal, and since my paper was published, I find the monthly quantity is increased to 2900 bushels, the time including winter months, when there is more water to draw, and the depth of the mine is somewhat increased. The average duty of the engines has in the same time advanced to near $70,000,000$; and calculating as before, $70,000,000$ is to 20,000 as 9360 is to 2674 , which shows a very near approximation to what would be inferred from the actual quantity of coal supplied.

There is therefore every kind of proof that the application of steam has been improved so as to occonomize fuel in Cornwall, 
wall, and that the rate of improvement has been well expressed by the printed reports. The same system and the same mode of estimating duty have been adopted in the lead-mines in Flintshire, and the advantages are sufficiently manifest. I can add that I now receive a regular duty paper from Mexico, showing the great advantage that the steam-engines at Real del Monte have derived from the application of the later improvements to them.

The evidence has been long before the public; and your predecessor Dr. Tilloch, who indeed was interested with $\mathrm{Mr}$. Woolf, repeatedly published statements in the early numbers of the Philosophical Magazine. Mr. Farey visited Cornwall with a view to investigate this subject, and this he did as long ago as 1818. He conducted an experiment on one of Woolf's engines, then working at Wheal Abraham, and the result was in his opinion conclusive. The learned President of the Royal Society, who has had longer acquaintarice with the progress of improvement of steam-engines in Cornwall than almost any other person, and who was in the year 1798 one of five individuals to whom disputes relative to the real performance of $\mathrm{Mr}$. Watt's engines were referred, has illustrated the subject in two papers read before the Royal Society: one printed in the Transactions for 1827; and the second in the present session, just published. He quotes in both the duty papers as authorities to be relied on; and in the latter, states that the best engine, which is the same that Mr. Rennie has taken for experiment, performed a duty in the whole month of December 1829, exceeding the average of 17 engines on Mr. Watt's construction in 1793 , by a proportion of nearly 4 to 1 .

My paper in the "Records of Mining" was published in the early part of last year; and as it was noticed in your fifth volume, I shall only say that I considered the account there given of the progress of improvement from year to year as the most interesting part of it, particularly as a great portion is taken from documents which are not in the hands of many. The results are quoted in your pages.

I trust and hope Mr. Rennie's opinion and conclusions on this interesting subject may also be communicated in some manner to the public, and that it may be strictly investigated by those who may continue to doubt.

As much has been said about the motives of those who publish statements on this subject, I must be allowed to repeat for myself and other adventurers in the mines in Cornwall, that we have no interest whatever in inducing others to give credit to those statements. We know that we are reap- 
ing great advantage from the use of certain improvements, and we might be content to keep this knowledge to ourselves.

We are not the manufacturers of the engines, but the purchasers of them; we have no monoply to maintain, or any other advantage to enjoy, but what may be shared by every individual who may wish to employ similar machines; but we do feel it to be an act of justice to those ingenious men, by whose labours we have benefited, to bear testimony to the success of their efforts : and as, since the time of Boulton and Watt, no one who has improved our engines has reaped pecuniary reward, it is at least fair that they should have credit for their skill and exertion. We are not the partisans of any individual artist, we avail ourselves of the assistance of many; and the great scale upon which we have to experiment, makes the result most interesting to us.

In the last year, besides màny smaller engines for winding and stamping, the mines in which $I$ am interested in Cornwall and Wales, employed 25 steam-engines for pumping, of which 17 have cylinders from 60 to 90 inches in diameter: their consumption of coal was 495,434 bushels; and a due regard to the oeconomy of the application of so vast a power is sufficient to interest me in every thing by which it may be promoted.

London, May 25, 1830.

JoHN TAYLOR.

LXII. On the Dying Struggle of the Dichotomous System. By W. S. MACLeAY, Esq. M.A. In a Letter to N. A. Vigors, Esq. F.R.S.* My Dear Vigors,

SOME years have now elapsed since a gentleman, the sable $N$ hue of whose vesture, if not the smile on his countenance, betokened that he sbould be in peace with all men, came up from the North to London, and announced himself to me as the Rev. John Fleming, D.D., Minister of Flisk, N. B. Considering him to be entitled to my services, as being a labourer in the same vineyard with myself, I of course showed him all the attention in my power. I knew him indeed at the time only by two or three articles in the Supplement to the Encyclopædia Britannica, which, if they be not fair specimens of a Scotch D.D.'s usual quantum of Greek, will at least remain a monument of his talent for writing on animals that he not only never saw, but would not even now know if he saw them. In addition to these truly novel specimens of Entomological

* Communicated by N. A. Vigors, Esq. 